\title{
TRILHOS DA RIBEIRA: MARCAS DO PASSADO, CAMINHOS PARA O FUTURO
}

TRILLOS DE LA RIBEIRA: MARCAS DEL PASADO, CAMINOS PARA EL FUTURO

TRACKS OF RIBEIRA: MARKS OF THE PAST, PATHWAYS FOR THE FUTURE

\section{BRASIL, AMÍRIA}

Doutora pela Universidade de São Paulo (USP), Professora Adjunta do Departamento de Arquitetura e Urbanismo da Universidade Federal do Rio Grande do Norte UFRN. E-mail: amiriabrasi@@gmail.com

\section{ANDRADE, CAIO}

Estudante do Curso de Arquitetura e Urbanismo da Universidade Federal do Rio Grande do Norte - UFRN. E-mail: caioandrade.au@gmail.com

\section{VIANA, DANIEL LUCAS}

Estudante do Curso de Arquitetura e Urbanismo da Universidade Federal do Rio Grande do Norte - UFRN. E-mail: daniel.lucasviana@gmail.com

\section{GOMES, DÉBORA}

Estudante do Curso de Arquitetura e Urbanismo da Universidade Federal do Rio Grande do Norte - UFRN. E-mail: debora.mendes37@gmail.com

\section{LOPES, FLÁVIA}

Mestre em Arquitetura e Urbanismo pela Universidade Federal do Rio Grande do Norte - UFRN. E-mail: flaviamnsı@hotmail.com

\section{GOMES, ISADORA}

Mestre em Engenharia de Produção pela Universidade Federal do Rio Grande do Norte - UFRN. E-mail: isadora_cmg@yahoo.com.br

\begin{abstract}
1 INTRODUÇÃO
O projeto apresentado neste artigo tem o objetivo principal de regenerar o bairro Ribeira, Natal, RN, considerando a sua história, valor patrimonial e identidade cultural. A proposta está pautada por soluções sustentáveis, de baixo custo, alinhadas com a realidade local e que possam colaborar com o resgate da vitalidade urbana, atraindo um maior número de pessoas para utilizar o local, ressaltando sua importância cultural e econômica para o cenário da cidade. As proposições apresentadas focam na construção e reforma de elementos arquitetônicos que emolduram as belezas naturais da área, gerando cenários magnéticos convidativos ao estar e ao permanecer, bem como na reestruturação de parte da infraestrutura local.
\end{abstract}

O conceito principal faz analogia aos trilhos do trem, elemento que permeia a poligonal de intervenção e ajuda a remontar um cenário que em tempos mais antigos foi o símbolo do desenvolvimento econômico, cultural e intelectual da área e da cidade, aspectos que esta equipe busca resgatar através deste projeto.

Para o desenvolvimento da proposta foi realizada uma análise SWOT ${ }^{1}$, elencando aspectos referentes à forças e fraquezas do ambiente da poligonal de atuação, ponderando a partir disso oportunidades para a intervenção e possíveis ameaças que algumas modificações positivas pudessem atrair. Com o resultado da análise, e dado o tempo hábil para o desenvolvimento da proposta, a equipe pensou em 18 ações, dentre as quais se destacam 03 grandes eixos de intervenção: (i) Intervenção na Avenida Tavares de Lira - com o propósito de valorizar visuais paisagísticas e de resgatar e consolidar atividades comerciais e culturais na área; (ii) Novo Terminal de Ônibus Urbano - com a finalidade de melhorar a mobilidade na área, proporcionando mais conforto e comodidade aos usuários do transporte público local; (iii) Renovação das

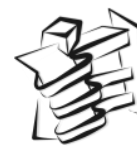


Áreas Públicas - inclusive, com reforma da infraestrutura de ruas, calçadas e passeios públicos, com o objetivo de aperfeiçoar a caminhabilidade dos pedestres e a mobilidade de veículos no local.

Figura 1: Mapa de Estratégias Traçadas a Partir da análise SWOT.

\begin{tabular}{|c|}
\hline 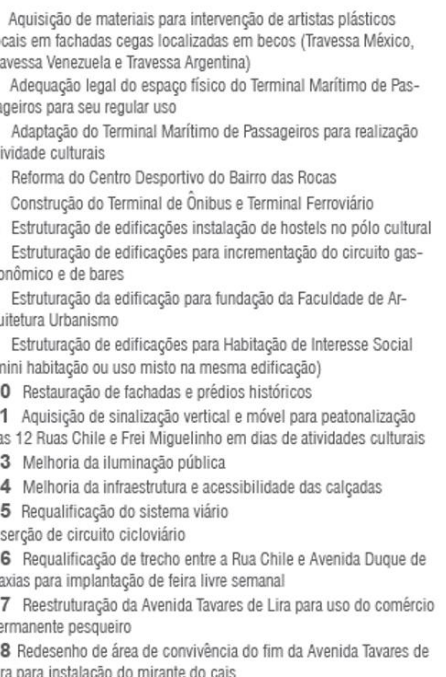 \\
\hline
\end{tabular}

Lira para instalaçấo do mirante do cais

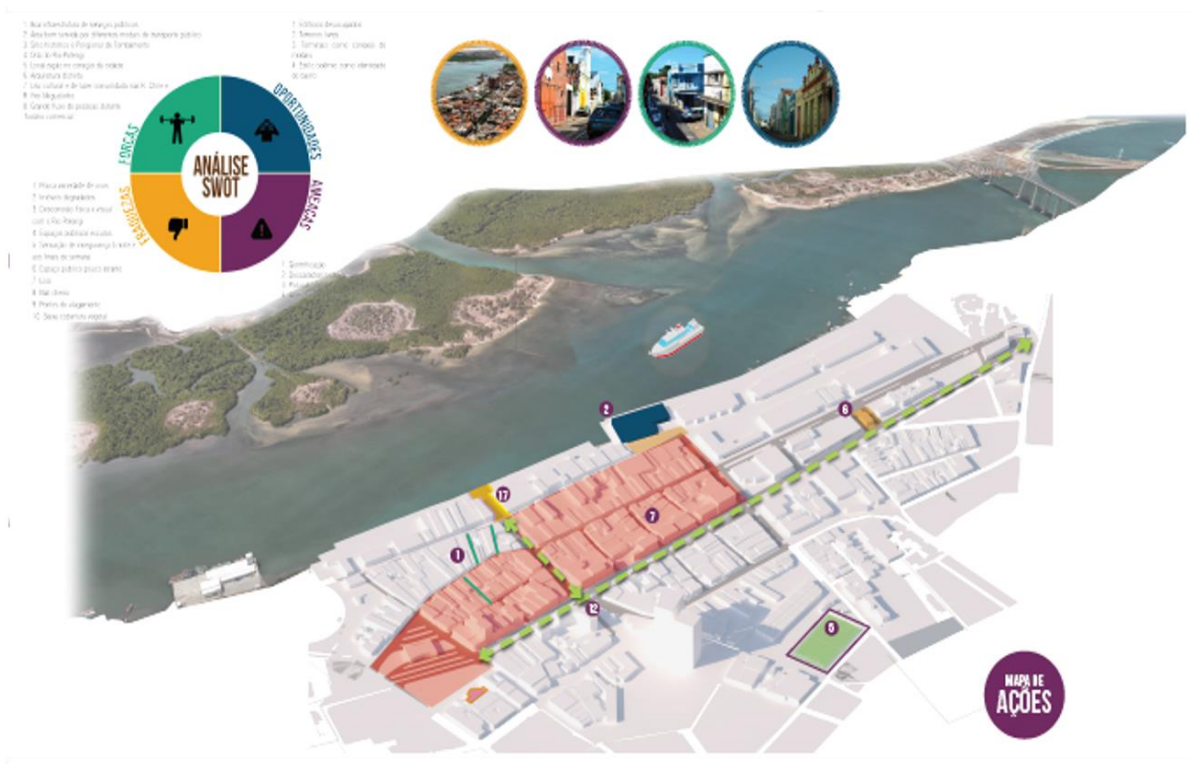

Fonte: Acervo da equipe Trilhos da Ribeira.

\section{A RIBEIRA NO TRILHO CERTO}

Para o desenvolvimento da proposta, que objetiva regenerar a vida pública e cultural da área, bem como a economia local, a equipe, com base na matriz da análise SWOT, definiu uma lista com 18 ações, que variam entre intervenções para melhoria da mobilidade - de pedestres, ciclistas e veículos - e reestruturação das edificações, incentivo à cultura local e melhoria da infraestrutura urbana do bairro. Entre as propostas, três ações entraram no detalhamento da segunda fase do concurso: (i) Intervenção na Avenida Tavares de Lira; (ii) Novo Terminal de Ônibus Urbano; (iii) Renovação de Áreas Públicas. Tratam-se de ações de baixo custo, que podem trazer resultados significativos e contribuir com o sucesso da proposta.

Com base na leitura histórica, evolutiva e morfológica do bairro - feita a partir do material disponibilizado pela organização do concurso UrbanLab Brasil - e visitas in loco para entender a situação atual, percebeu-se que a Avenida Tavares de Lira - apesar da sua importância, por ser ponto de confluência de moradores e visitantes do bairro Ribeira, local de grande valor visual e de intensa atividade comercial - é minimamente infraestruturada para dar suporte às atividades desenvolvidas no local. Para o resgate da área buscou-se reestruturar o pequeno núcleo comercial existente realocando-o para as laterais da rua e liberando as visuais da orla, transformando o espaço central em uma área de convivência e de apreciação das belezas naturais locais. Para essas laterais da rua, nova área comercial, foram propostas estruturas fixas de cobertura e mesas para exposição de produtos, além da infraestrutura necessária para o desenvolvimento das atividades.

Para a orla local, foi pensada uma cobertura com a mesma identidade visual da intervenção arquitetônica das laterais da avenida que também poderá servir como um passeio e mirante público. A intervenção visa converter o trecho entre a Rua Chile e o Rio Potengi em via de pedestres, com infraestrutura adequada. É importante salientar que a proposta buscou preservar as árvores existentes, bem como o canteiro central da avenida com os dois monumentos.

Além desse núcleo comercial fixo no local, a proposta contempla uma intervenção efêmera para os finais de semana: uma feira livre. A ideia é de que o eixo da Avenida Tavares de Lira - entre a Rua Chile e a Avenida Duque de Caxias - seja utilizado por comerciantes locais com novos mobiliários de apoio às atividades previstas (barracas). 
Brasil, A.; Andrade, C.; Viana, D. L.; Gomes, D.; Lopes, F.; Gomes, I.

Figura 2: Proposta de Intervenção da Avenida Tavares de Lira.

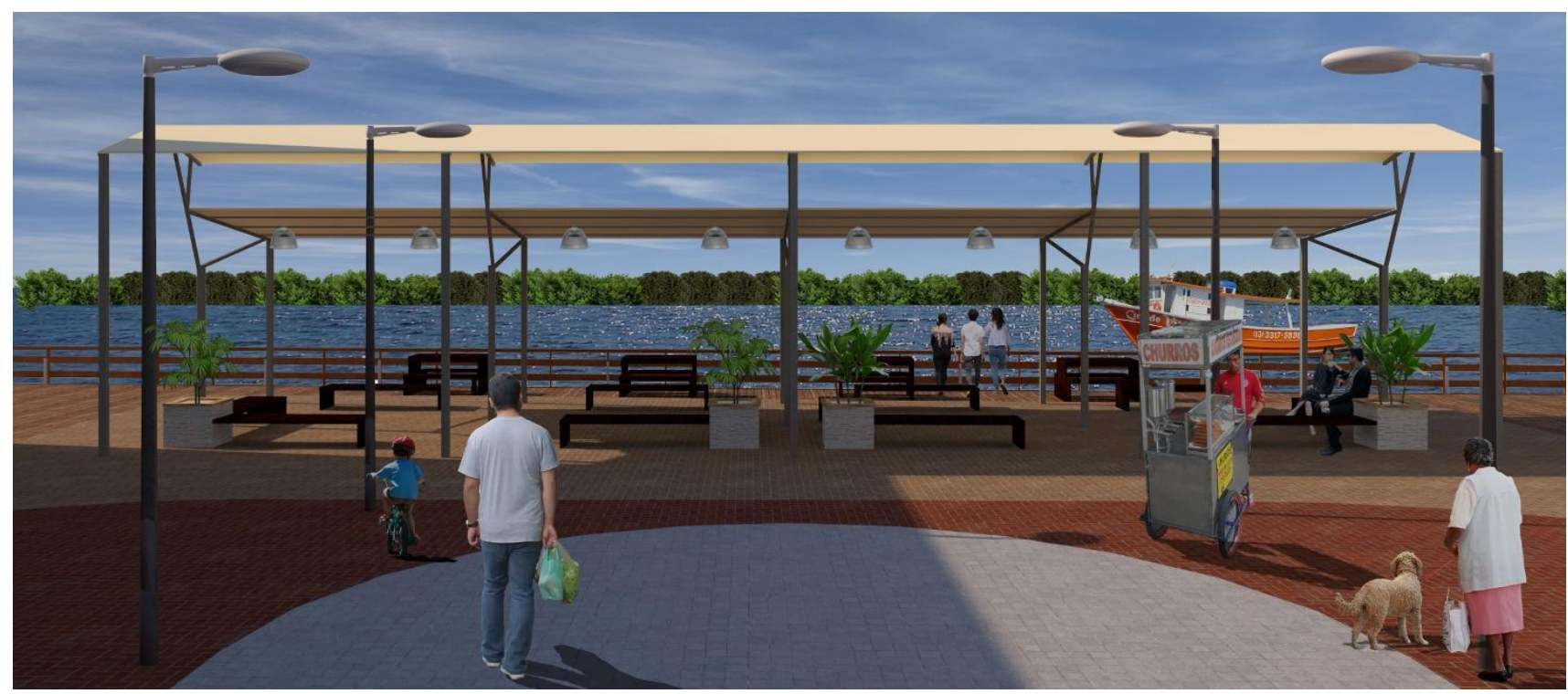

Fonte: Acervo da equipe Trilhos da Ribeira.

Figura 3: Detalhamento da Proposta de Intervenção da Avenida Tavares de Lira.

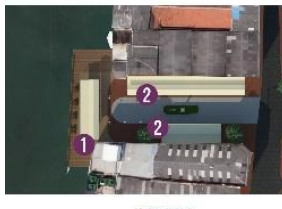

LEGENDA

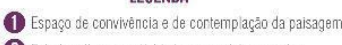

(2) Estrutura tiva para aliviciade comeccia pesqueira

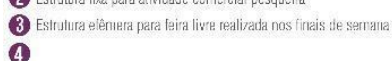

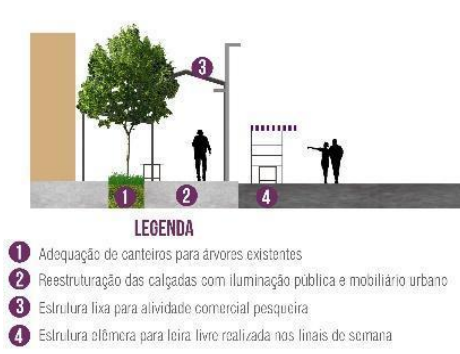

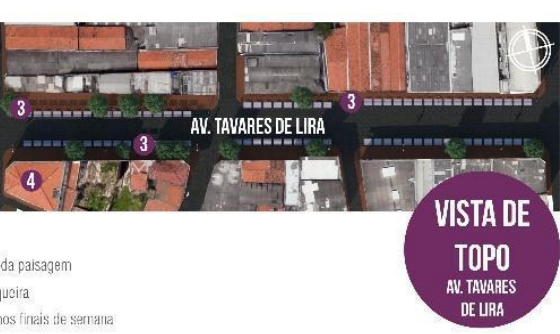

N. TAVARES
DE URA

$+9$
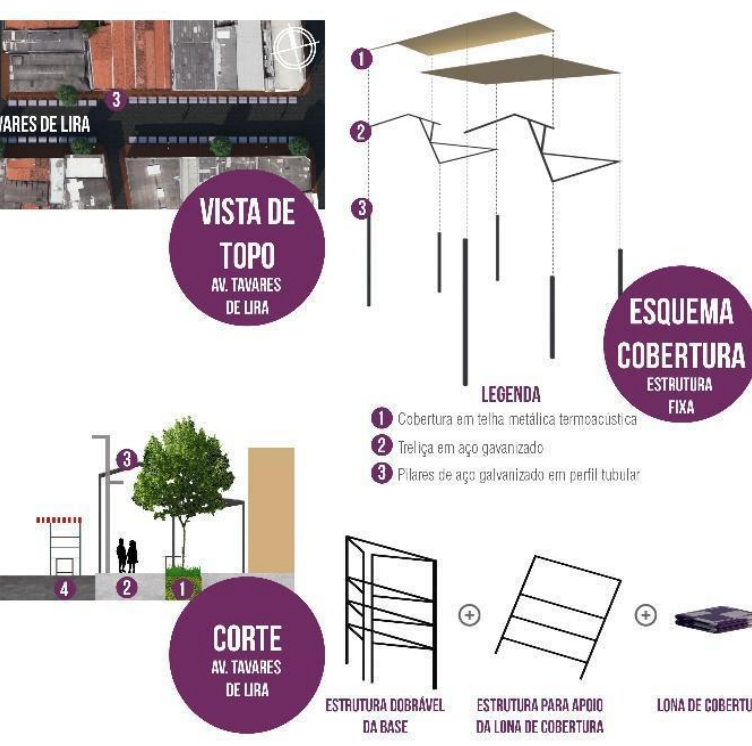

Cobertura en talha metalic

2 Trelliga em aço gavanizado

(3) Plakes de aço galvanizado ent perili tubulat

(.)

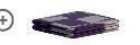

LONA DE GOBERTURA

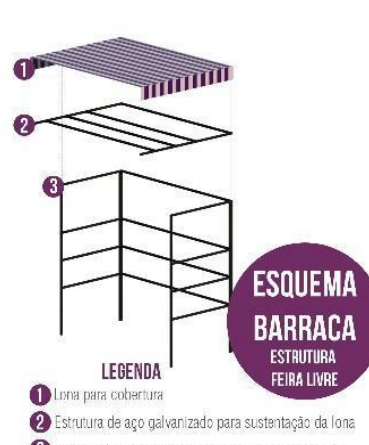

(3) Estu ura dobráwel oc aco galvanizado para apoio da

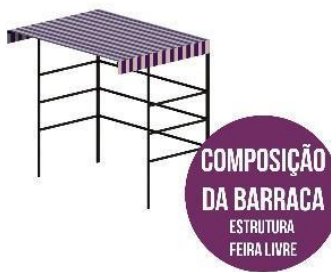

Fonte: Acervo da equipe Trilhos da Ribeira.

Intervenções como a da Avenida Tavares de Lira, potencialmente, atrairiam mais movimento para a Ribeira, não só de moradores, como de visitantes de outros bairros da cidade. Considerando esse potencial aumento do fluxo de usuários na área, a equipe propôs: a reestruturação do terminal de ônibus já existente no local e a implantação de infraestrutura nos passeios públicos.

O terminal de ônibus urbano da Ribeira pretende se constituir um importante equipamento dentro da lógica de modais de transporte público da cidade, principalmente pela sua proximidade ao terminal ferroviário que carrega inúmeros passageiros por dia, em viagens para Natal e cidades vizinhas. Tendo em vista a sua relevância, a edificação que, hoje, abriga o terminal de passageiros será recuperada através de uma intervenção arquitetônica despretensiosa, mas eficaz, que proporcionará conforto aos passageiros dentro do contexto urbano em que se insere.

A nova estrutura para o Terminal de Ônibus é proposta com a mesma identidade visual dos equipamentos e mobiliários sugeridos para o Eixo Comercial da avenida Tavares de Lira. A intenção é de que os usuários tenham mais comodidade e conforto ao optar pelo ônibus, e assim incentivar o uso do transporte público. $\mathrm{O}$ 
novo terminal conta com banheiros públicos acessíveis, ampla área de convivência, novo mobiliário e canteiros com vegetação de médio porte que proporcionará um melhor conforto térmico e tratamento paisagístico para o local.

Figura 4: Proposta de Intervenção no Terminal de Ônibus Urbano.

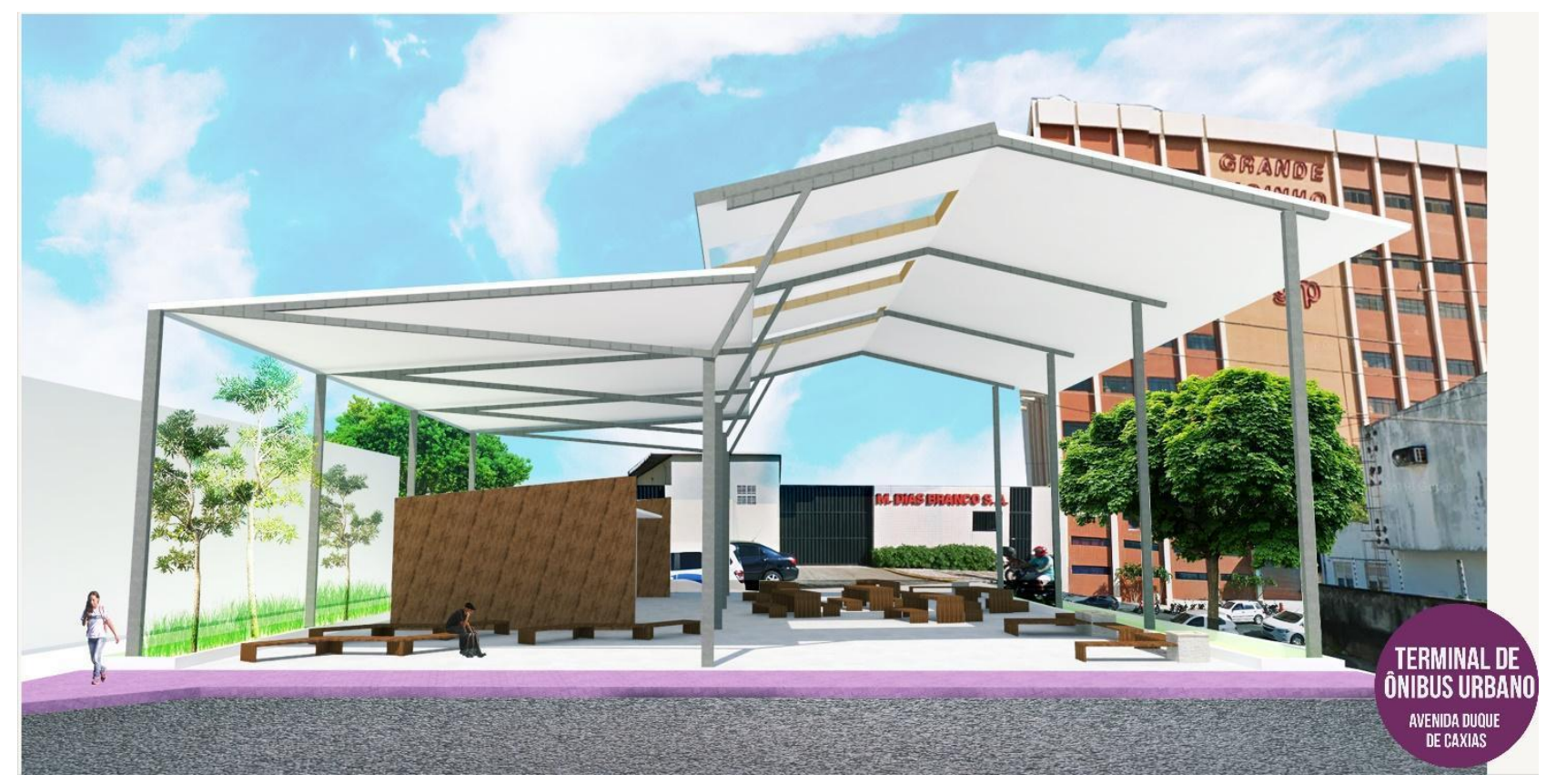

Fonte: Acervo da equipe Trilhos da Ribeira.

O potencial aumento do movimento local pela intervenção no eixo comercial da Avenida Tavares de Lira também impulsionou propostas de recuperação da infraestrutura do eixo da Avenida Duque de Caxias, principal via arterial do bairro e local de acesso para a Tavares de Lira.

A diminuição do canteiro central do local permitirá o alargamento de calçadas, as quais passarão a seguir os critérios estabelecidos pelo Ministério das Cidades em relação às dimensões mínimas para passeios mais confortáveis aos usuários. Esse redimensionamento garante a implantação de faixa de serviço para instalação de novo mobiliário urbano e plantio de árvores, uma ação considerada importante já que a Ribeira é um dos bairros natalenses com menor cobertura vegetal. Além do passeio de pedestres também foi pensada a construção de uma ciclovia em dimensões já sugeridas e previamente pensada pelo poder público municipal de Natal, pois trata-se de uma rota prevista no plano cicloviário do município.

A ideia é que essa intervenção na Avenida Duque de Caxias, implantada sob o cenário de fachadas ecléticas históricas da Ribeira, possa imprimir novo charme ao bairro e passe a atrair visitantes. Ademais, seja um modelo para outros redesenhos viários por toda a cidade. 
Figura 5: Proposta de Intervenção Viária na Avenida Duque de Caxias.

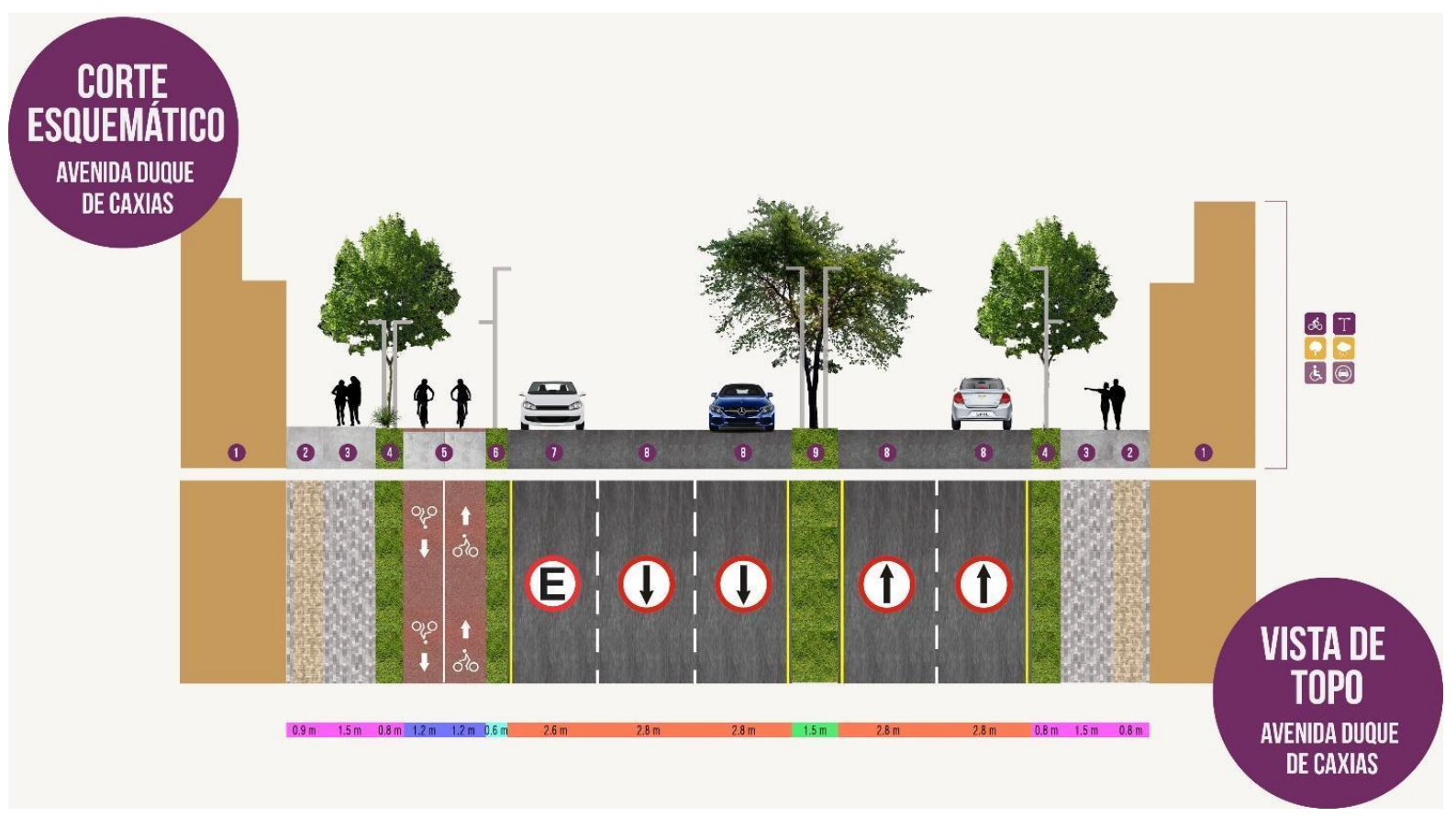

Fonte: Acervo da equipe Trilhos da Ribeira.

A intenção é de que a implementação do projeto seja organizada em três grandes fases: (i) seminários de debate e apresentação de propostas junto à comunidade; (ii) implementação das obras de mobilidade e infraestrutura urbana e (iii) possíveis intervenções em propriedades de caráter privado. A estimativa inicial é de que o custo para a implantação total do projeto seja de 25.000.000 USD. Para explicitar melhor as etapas, ideias de implementação e custos, a equipe estruturou um diagrama de GANTT, um cronograma físico/financeiro no qual foram estabelecidos marcos para indicar o tempo estimado, a conclusão e o valor de cada fase do que está proposto.

Figura 6: Cronograma Físico/Financeiro da Proposta.
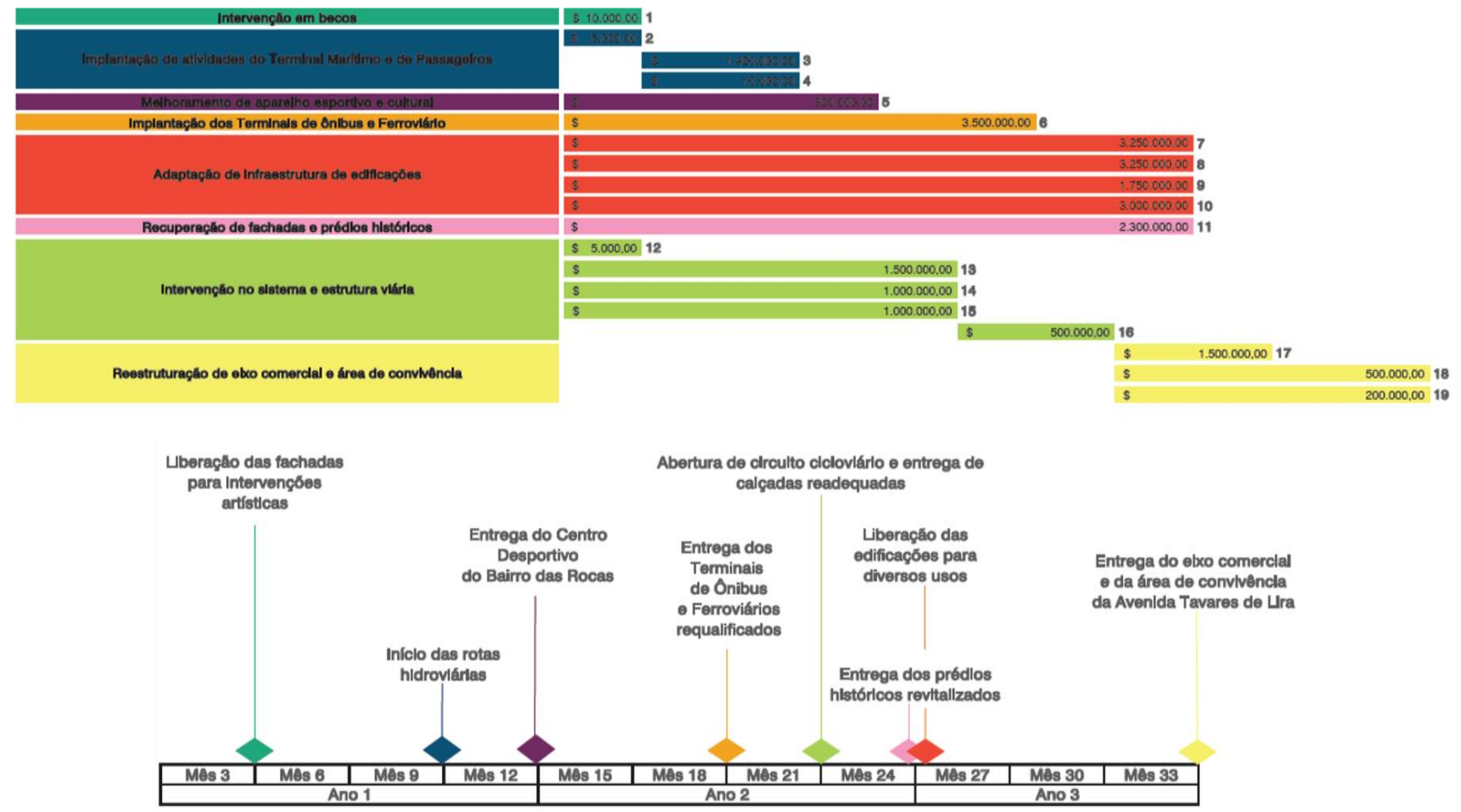

Fonte: Acervo da equipe Trilhos da Ribeira. 


\section{CONSIDERAÇÕES FINAIS}

A participação no concurso BID UrbanLab, além de representar um espaço oportuno para desenvolver o pensamento urbanístico e uma proposta projetual crítica para o bairro Ribeira, também trouxe desafios de ordem teórica e prática para os participantes. Inicialmente, a equipe constatou o desafio de lidar com uma área central de ocupação consolidada, de reconhecida importância histórica e com declarado valor patrimonial com distintas naturezas (edilícia, paisagística e urbanística). Com base nessa constatação, foi desenvolvida uma proposta de "regeneração" do bairro, a fim de evidenciar as suas potencialidades, respeitando o espaço preexistente, as relações de escala e de proximidade com os usuários, assim como mirando na solução de problemas por meio do desenho urbano. Para tanto, considerar a complexidade de relações que se estabelecem no bairro se tornou imprescindível. A equipe buscou trabalhar com diferentes escalas de projeto, articulando intervenções de ordem local que pudessem ter desdobramentos no bairro e na cidade. Além disso, os projetos consideraram demandas sociais e restrições econômicas, preliminares, disponibilizadas nos termos de referência pela organização do concurso. Foram apresentados a partir do pressuposto de que as suas implementações devem estar alinhadas a políticas urbanas comprometidas com o acesso e com o uso democratizado de espaços públicos (com adequada infraestrutura), com o direito à memória e com o direito à cidade.

\section{REFERÊNCIAS}

BRASIL. Ministério das Cidades. Instituto do Patrimônio Histórico e Artístico Nacional. Implementação de ações em áreas urbanas centrais e cidades históricas: manual de orientação. Brasília-DF: IPHAN: Ministério das Cidades, 2011. 252p.

NATAL. Instrumentos de Ordenamento Urbano. Natal: Prefeitura Municipal do Natal. Secretaria Municipal de Meio Ambiente e Urbanismo. 2009.

NATAL. Prefeitura Municipal. Plano de melhoria de circulação viário: proposta cicloviário da cidade do Natal. Disponível em: https://pt.slideshare.net/NatalPrefeitura/plano-ciclovirio-de-natal-atualizado . Acesso em julho/2018.

TINOCO, M. B. DE M.; SOBRINHA, M. D. P. B.; TRIGUEIRO, E. B. F. (Org.). Ribeira: Plano de Reabilitação para Áreas Centrais. Natal: Edufrn, 2008. 249 p. Disponível em: http://www.gbv.de/dms/tib-ub-hannover/757515452.pdf. Acesso em: 08 jun. 2016.

\section{NOTAS}

${ }^{1} \mathrm{O}$ termo S.W.O.T. originado das palavras em inglês Strenghts, Weaknesses, Opportunities e Threats, as quais respectivamente significam Forças, Fraquezas, Oportunidades e Ameaças. Disponível em https://bit.ly/1DSIdBL, acesso em 04 de julho de 2018.

NOTA DO EDITOR (*) O conteúdo do artigo e as imagens nele publicadas são de responsabilidade do(s) autor(es). 